\title{
Erratum to: Purification and properties of an extracellular esterase from a cold-adapted Pseudomonas mandelii
}

\author{
Seunghee Hong $\cdot$ ChangWoo Lee $\cdot$ Sei-Heon Jang
}

Published online: 10 April 2012

(C) Springer Science+Business Media B.V. 2012

Erratum to: Biotechnol Lett

DOI 10.1007/s10529-012-0866-y

The authors have noticed an error in the calculation of the $\mathrm{k}_{\mathrm{cat}}$ of EstK. In the "Results and discussion" section, it should state that the $\mathrm{k}_{\text {cat }}$ of EstK was $2.3 \mathrm{~s}^{-1}$. The authors apologize for the error.

The online version of the original article can be found under doi:10.1007/s10529-012-0866-y.

S. Hong $\cdot$ C. Lee $\cdot$ S.-H. Jang $(\bowtie)$

Department of Biomedical Science, Daegu University,

Gyeongsan 712-714, Korea

e-mail: shjang@daegu.ac.kr

S. Hong

e-mail: cookie9hee@nate.com

C. Lee

e-mail: leec@daegu.ac.kr 